\title{
Recurrence risk after neural tube defects in a genetic counselling clinic
}

\author{
ANDREW CZEIZEL AND JULIA MÉTNEKI \\ From the Department of Human Genetics, National Institute of Hygiene, Budapest, Hungary.
}

SUMMARY The recurrence of isolated neural tube defects in a population of women from a genetic counselling clinic was found to be $3.4 \%$. After one baby with a neural tube defect the recurrence was $2.3 \%$. Of the 15 pregnancies of women who had two previous babies with neural tube defects, there were three further recurrences. These findings show that the Hungarian recurrence risk of isolated neural tube defects has not changed with a declining birth prevalence, and that the rate in genetic counselling clinic patients is the same as in a previous population based epidemiological study.

In Hungary, the birth prevalence of isolated neural tube defects (NTD) has steadily declined over the last two decades. ${ }^{1}$ In the 1960 s it was $2 \cdot 80$, in the period 1970 to 1974 it was $2 \cdot 24$, and in 1979 to 1981 it was 1.48 per 1000 total births. ${ }^{2}$ This reflects a general trend which appears to be world-wide, for decreasing prevalences in recent years have been reported in, for example, Northern Ireland, England and Wales, Atlanta (USA), Canada, Denmark, Sweden, Finland, ${ }^{3} 4$ New York, ${ }^{5}$ the Netherlands, ${ }^{6}$ and Australia. ${ }^{7}$ A correlation has been found in the past between the general occurrence and the occurrence in sibs, that is, recurrence, the latter being about ten times higher than the birth prevalence. ${ }^{8}$ Data on recurrence of NTD within sibships are derived from epidemiological studies, and the risks of recurrence probably also decline with time in the same manner as occurrence. ${ }^{9}$ In Hungary, a large epidemiological study performed in index patients born in 1962 to 1967 found the recurrence risk in sibs to be $3 \cdot 1 \%{ }^{10}$ and this is the Hungarian figure used today in genetic counselling. A recent study by Seller ${ }^{11}$ showed, however, that there is a slightly, although not significantly, lower recurrence of NTD in a genetic counselling clinic population in south-east England than in the more general population from which epidemiological data are derived.

In view of the overall general decline in occurrence and probably also of recurrence of isolated NTD since our original study on recurrence risks, and, secondly, the possibility that couples who present for genetic counselling may be at a slightly lower

Received for publication 5 November 1983.

Accepted for publication 9 March 1984. risk for recurrence than the general population, we have examined retrospectively the recurrence of NTD in patients attending our Genetic Counselling Clinic in the period 1975 to 1980.

\section{Materials and methods}

All consultands with NTD probands who attended the Genetic Counselling Clinic of the National Institute of Hygiene, Budapest, from 1 January 1975 to 31 December 1980, including any subsequent pregnancies up to 31 December 1981, are included in the study. Data, including necropsy findings, on all probands and any affected sibs were documented. Neural tube defects, that is, anencephaly, (including anencephaly and spina bifida cystica, iniencephaly) and encephalocele and spina bifida cystica with or without their secondary associated congenital anomalies (for example, congenital hydrocephalus or club foot) were separated into groups. The so-called 'isolated' NTD group included only NTD without other major congenital anomalies, while in the so-called 'multiple' abnormality group NTD were associated with other major congenital anomalies, for example, Meckel-Gruber syndrome and schisis-association. ${ }^{12}$ Consultands were sent a reply-paid postal questionnaire which asked for details of pregnancies subsequent to their visit to the clinic. Additional data were obtained from the Hungarian Congenital Malformation Registry of the Centre for Congenital Anomaly Control, for almost all births with NTD have been recorded in that registry since 1970. Many of the women were also followed up through the national programme for the prevention of recurrence of 
NTD which has been operating in Hungary since $1974 .{ }^{13}$ Through it, women at risk are informed about the availability of genetic counselling and antenatal diagnosis. The take-up rate of these services is high at over $90 \%$.

\section{Results}

There were 305 consultands who attended our clinic because of a proband with NTD in the study period. Of these, 273 replied to the questionnaire. Ascertainment was thus $89.5 \%$. However, none of the remaining 32 consultands was reported to the Hungarian Congenital Malformation Registry as having a subsequent NTD child. Of the 305 patients, 274 had one child with NTD and $23(7 \cdot 7 \%)$ had two affected children, while eight $(2.4 \%)$ had one child with multiple abnormalities including NTD (table 1). An attempt was made in these eight cases to identify and classify them in the Genetic Counselling Clinic. They were evaluated separately because their origin may differ (Meckel-Gruber syndrome is an autosomal recessive condition) or they may differ in aetiology (schisis-association) from the multifactorial type of NTD being considered in this study.

In the isolated NTD group, anencephaly with or without spina bifida cystica occurred with almost the same frequency as spina bifida cystica alone. In families where there were two children affected by isolated NTD, there was concordance in the type of abnormality in 12 cases (52\%). Seven sib pairs had spina bifida and five had anencephaly with or without spina bifida. There was discordance in 11 families $(48 \%)$.

The previous reproductive history of the 305 consultands in the study is shown in table 2 . There was a total of 635 pregnancies and 328 produced isolated or multiple NTD. Within the isolated NTD group the spontaneous abortion rate was $15.8 \%$ and

TABLE 1 Type of NTD of previous affected children.

\begin{tabular}{|c|c|c|}
\hline Group and type of abnormality & No & $\%$ \\
\hline \multicolumn{3}{|l|}{ Isolated NTD } \\
\hline Anencephaly & 113 & $35 \cdot 3$ \\
\hline Anenecephaly + spina bifida cystica & 36 & $11 \cdot 3$ \\
\hline Spina bifida cystica & 162 & $50 \cdot 6$ \\
\hline Encephalocele & 9 & $2 \cdot 8$ \\
\hline Total & 320 & $97 \cdot 6$ \\
\hline \multicolumn{3}{|l|}{ Multiple abnormality including NTD } \\
\hline Spina bifida cystica + anal atresia (Duhamel?) & 3 & \\
\hline Spina bifida cystica + renal agenesis (Duhamel?) & 2 & \\
\hline Spina bifida + cleft lip and palate (schisis) & 1 & \\
\hline $\begin{array}{l}\text { Occipital encephalocele }+ \text { cystic kidney disease } \\
\text { (Meckel-Gruber) }\end{array}$ & 1 & \\
\hline $\begin{array}{l}\text { Occipital encephalocele }+ \text { cleft lip and palate } \\
\text { (schisis) }\end{array}$ & 1 & \\
\hline Total & 8 & $2 \cdot 4$ \\
\hline Total & 328 & \\
\hline
\end{tabular}

TABLE 2 Previous reproductive history of 305 consultands in study.

\begin{tabular}{lrr}
\hline Group and type of abnormality & No & \multicolumn{1}{c}{$\%$} \\
\hline Isolated NTD & 320 & 51.6 \\
Termination of pregnancy & 77 & 12.4 \\
Spontaneous abortion & 98 & 15.8 \\
Ectopic pregnancy & 1 & 0.2 \\
Stillbirth & 5 & 0.8 \\
Livebirth & 119 & 19.2 \\
Total & 620 & 100.0 \\
& & \\
Multiple abnormality including NTD & 8 & 53.3 \\
Termination of pregnancy & 3 & 20.0 \\
Spontaneous abortions & 1 & 6.7 \\
Livebirth & 3 & 20.0 \\
Total & 15 & 100.0 \\
\hline
\end{tabular}

the termination of pregnancy for social or other reasons was $12.4 \%$. Fifteen livebirths $(3.4 \%$ of total births) had congenital abnormalities other than NTD. These are listed in table 3 and no one type of abnormality predominated.

Of the 305 consultands, 273 replied to the questionnaire about further pregnancies and so are included in the recurrence study. A total of 241 had one or more subsequent pregnancy by the end of the study period, 187 women already being pregnant at the time of the consultation and a further 54 becoming pregnant later. There was a total of 274 pregnancies including two twin pairs and thus 276 offspring ar included in the analysis.

The outcome of the pregnancies is shown in table 4, before and after midtrimester amniocenteses which were performed on all but six consultands studied. There were eight recurrences of NTD in the isolated NTD group. Four of these pregnancies were terminated following antenatal diagnosis by ultrasonic examination or midtrimester amniocentesis and amniotic fluid AFP assay or both. Of the four

TABLE 3 Abnormalities other than NTD in sibs of probands before birth of proband.

Hydrocephalus*

Klippel-Feil syndrome

Diaphragmatic anomaly

Cleft lip and palate

Ventricular septal defect

Exstrophy of cloaca

Biliary atresia

Lung hypoplasia

Congenital dislocation of hip

Malrotation of intestine

Club foot

Haemangioma

Congenital glaucoma (buphthalmos)

Multiple abnormality $\dagger$

Total

*Caused by meningitis and ventriculitis, and haemorrhagic cerebri, respectively.

TThis unspecified abnormality occurred in a female stillborn pair of an anencephalic twin. Necropsy was not performed. 
TABLE 4 Outcome of pregnancies following birth of NTD proband.

\begin{tabular}{|c|c|c|}
\hline Group and type of abnormality & No & Year of birth \\
\hline \multicolumn{3}{|l|}{$\begin{array}{l}\text { Isolated NTD } \\
\text { (Before midtrimester examination) }\end{array}$} \\
\hline $\begin{array}{l}\text { Termination of pregnancy for social reasons } \\
\text { Induced abortion due to maternal }\end{array}$ & 4 & \\
\hline hyperthyroidism & 1 & \\
\hline Spontaneous abortion & 26 & \\
\hline \multicolumn{3}{|l|}{ (After midtrimester examination) } \\
\hline $\begin{array}{l}\text { Termination of pregnancy owing to } \\
\text { chromosome abnormality } \\
(46, X X, 15 p+)\end{array}$ & 1 & \\
\hline to intrauterine death & 1 & \\
\hline to false positive amniotic AFP & 1 & \\
\hline to NTD & 4 & $\begin{array}{l}1975,1977 \\
1978,1979\end{array}$ \\
\hline Spontaneous abortion & 2 & \\
\hline Stillbirth (fetus had no anomalies) & 1 & \\
\hline Livebirth with NTD & 4 & $\begin{array}{l}1975,1977 \\
1978,1979\end{array}$ \\
\hline \multicolumn{3}{|l|}{ With other major abnormalities } \\
\hline $\begin{array}{l}\text { With minor anomalies (unstable hip } 2 \text {, } \\
\text { inguinal hernia, undescended testis) }\end{array}$ & 4 & \\
\hline $\begin{array}{l}\text { Without anomalies } \\
\text { Total }\end{array}$ & $\begin{array}{l}218 \\
269\end{array}$ & \\
\hline \multicolumn{3}{|l|}{ Multiple abnormality including NTD } \\
\hline examination) & 1 & \\
\hline Livebirth without anomalies & 6 & \\
\hline Total & 7 & \\
\hline
\end{tabular}

NTD livebirths, one had been diagnosed antenatally but the mother had refused termination of pregnancy, one had a normal ultrasonic picture and amniotic fluid AFP value and was thus a false negative, one was a closed lesion which had a normal amniotic AFP, and in the last case the mother had refused amniocentesis and the ultrasonic examination and the serum AFP had been normal. These four NTD were reported to the Hungarian Congenital Malformation Registry. No abnormality occurred in six subsequent sibs of the probands with multiple abnormalities including NTD.

The birth and fetal prevalence of NTD are separated in the Hungarian Congenital Malformation Registry and only the birth prevalance has been evaluated, though terminated NTD cases are also registered ${ }^{2}$ because of the Hungarian prevention programme. However, in this study the observed recurrence risk includes four antenatally diagnosed and terminated NTD cases. The NTD group has higher antenatal selection through spontaneously aborted fetuses. Thus, if our recurrence risk figure had taken only the birth prevalence into consideration, it would have been somewhat lower.

In calculating the overall recurrence risks, pregnancies ending in spontaneous abortion and terminations, except for NTD fetuses, were deducted from the total, as recurrences are normally taken from the newborn population. Thus, there were eight NTD out of a total of 233, an overall recurrence of $3.4 \%$ in the isolated NTD group. Separate risks were calculated for women who had one or two previous affected children. There were 23 women who had two previous children with NTD and 15 had further pregnancies, among which there were three recurrences. The recurrence risk for this group was therefore $20 \%$. The risk for those with only one previous affected child (five recurrences in 218) was $2 \cdot 3 \%$.

There were two serious and four mild abnormalities other than NTD. No one abnormality was more common than another.

\section{Discussion}

The overall recurrence of the multifactorial form of isolated NTD found in this genetic counselling clinic population $(3.4 \%)$ is similar to that found in a larger epidemiological study in Hungary in 1969 $(3.1 \%)^{10}$ and so has not changed with time and the declining birth prevalence. It is also the same as that found in a genetic clinic population in south-east England. ${ }^{11}$ However, since it is known that the risk of recurrence rises markedly with an increasing number of affected children, ${ }^{14}$ it is more meaningful to separate the population according to previous history. This then gives more precise data which is of practical use in genetic counselling clinics. In the present study the recurrence risk after one previous affected child was found to be $2 \cdot 3 \%$ and after two previous affected children $20 \%$. These figures differ, the former being lower and the latter higher, from those found in the study by Seller ${ }^{11}$ and from those normally quoted in genetic counselling clinics. ${ }^{14}$ This difference may be real, but it could also be an artefact produced by the relatively small sample involved in the current study.

It has long been recognised that NTD are not a single entity but a heterogeneous group. At least the more common type of isolated NTD of multifactorial origin and the relatively rare type of multiple abnormalities including NTD of different origin (for example, caused by major mutant genes, environmental factors) should be separated. Their epidemiological features (sex ratio, seasonality, recurrence risk) show significant differences. ${ }^{815}$ The proportion of these two groups is $6 \%$ to $94 \%$ in the Hungarian Congenital Malformation Registry. A recent study in the USA found that multiple NTD formed roughly $10 \%$ and isolated NTD $90 \%$ of the total. ${ }^{15}$ In the present study, the comparable figures were $2.4 \%$ and $97.6 \%$. However, the main source of our cases was the national programme for prevention of the recurrence of NTD and this programme involved only the isolated NTD cases. 
The birth prevalence of congenital anomalies other than NTD in sibs of probands with isolated NTD in the present study was $3.4 \%$ in those born before the proband and $2.6 \%$ in those born afterwards. This is not significantly different from the registered national figures for all births (about $4 \%$ ) and is consistent with the findings of Nevin and Johnston ${ }^{16}$ in Northern Ireland, where their occurrence was $2 \cdot 1 \%$. There was no preponderance of any particular abnormality. Taking all sibs, whether born before or after the proband, there was one isolated case of cleft lip and palate and one posterior cleft palate, an overall birth prevalence of $0.26 \%$, which is somewhat greater than expected $(0 \cdot 15 \%) .{ }^{17}$ In addition, there was one case of Klippel-Feil syndrome, ${ }^{18}$ and one of diaphragmatic anomaly which, togethe 1 with cleft lip and palate, may have some aetiological relationship with NTD. ${ }^{12}$ However, single cases are of little significance. The occurrence of two cases of hydrocephalus $(0.4 \%)$ was higher than the birth prevalence $(0.07 \%)$, but both cases were of a different type from those which are part of the NTD spectrum.

Spontaneous abortions have been implicated in the aetiology of isolated NTD. ${ }^{19} 20$ In particular, a spontaneous abortion before the NTD pregnancy has been implicated. ${ }^{21}$ Although the present study did not document the relationship in time between the spontaneous abortions and the NTD pregnancy, it is interesting to note in the previous reproductive history of the consultands that $15.8 \%$ of pregnancies ended in spontaneous abortion, which is significantly higher than the incidence in the Hungarian population during the study period $(8 \cdot 2 \%){ }^{22}$ The rate of spontaneous abortion, including one fetal death diagnosed antenatally, was $10.8 \%$ in subsequent pregnancies.

The point is that the Hungarian recurrence risk of isolated NTD has not changed with a declining birth prevalence and a similar rate was found in a previous population based epidemiological survey. This recent study of a genetic counselling sample also shows a similar recurrence risk. However, it is difficult to exclude the possible interaction of these two differences of the study sample, though owing to the high participation rate in the national progiamme for the prevention of the recurrence of NTD, there is little probability.

The authors thank Dr Mary J Seller for her comments and generous help in improving the manuscript.
References

1 Czeizel A. Spina bifida and anencephaly. Br Med J 1983; 287:429.

2 Czeizel A, Karig G. An analysis of the changing birth prevalences of neural tube defects in Hungary. Acta Morphol Acad Sci Hung 1984;32: (in press).

3 International Clearing House for Birth Defects Monitoring Systems. Annual Report 1981. Stockholm: Swedish National Board of Health and Welfare, 1983.

4 Mathers CD, Field B. Some international trends in the incidence of neural tube defects. Community Health Studies 1983;7:60-6.

5 Stein SO, Feldman JG, Friedlander M, Klein HJ. Is myelomeningocele a disappearing disease? Pediatrics 1982;69:511-4.

6 Romijn JA, Treffers PE. Anencephaly in the Netherlands. A remarkable decline. Lancet $1983 ; \mathrm{i}: 64-5$.

7 Danks DM, Halliday JL. Incidence of neural tube defects in Victoria, Australia. Lancet 1983;i:65.

8 Czeizel E. Etiology of neural tube defects (Hungarian). A Biológia Aktuális Problémái 1976;6:155-215.

9 Yen S, MacMahon B. Genetics of anencephaly and spina bifida. Lancet 1968 ;ii:623-6.

10 Czeizel A, Révész G. Major malformations of the central nervous system in Hungary. Br J Prev Soc Med 1970;24: 205-22.

11 Seller MJ. Recurrence risk for neural tube defects in a genetic counselling clinic population. J Med Genet 1981; $18: 245-8$.

12 Czeizel A. Schisis-association. Am J Med Genet 1981 ;10: 25-35.

13 Czeizel A, Kerekes J, Merétey K, et al. National proe gramme for prevention of the recurrence of neural tube defects. Acta Paediatr Acad Sci Hung 1979;20:315-9.

14 Carter CO, Roberts JAF. The risk of recurrence afte two children with central nervous system malformations Lancet 1967 ; : 306-8.

15 Khoury MJ, Erickson JD, James LM. Etiologic heterogeneity of neural tube defects: clues from epidemiology. Am J Epidemiol 1982;115:538-48.

16 Nevin NC, Johnston WP. A family study of spina bifida and anencephalus in Belfast, Northern Ireland (1964 to 1968). J Med Genet 1980;17:203-11.

17 Fraser FC, Czeizel A, Hanson C. Increased frequency of neural tube defects in sibs of children with other malformations. Lancet 1982 ;ii:144-5.

18 Carter CO, Evans KA, Till K. Spinal dysraphism: genetic relation to neural tube malformations. J Med Genet 1976;13:343-50.

19 Clarke CA, Habson D, McKendrick OM, Rogers SG, Sheppard PM. Spina bifida and anencephaly: miscarriage as a possible cause. $\mathrm{Br}$ Med $J$ 1975;4:743-6.

20 Evans DR. Neural tube defects: importance of a history of abortion and aetiology. Br Med J 1979;ii:975-6.

21 Gardiner A, Clarke C, Cowen J, Finn R, McKendrick OM. Spontaneous abortion and fetal abnormality in subsequent pregnancy. $\mathrm{Br}$ Med J 1978;i:1016-8.

22 Czeizel A, Bognár Z, Rockenbauer M. Some epidemiological data of spontaneous abortion in Hungary 19711980. J Epidemiol Comm Health 1984;38:143-8.

Correspondence and requests for reprints to $\mathrm{Dr}$ A Czeizel, Department of Human Genetics, National Institute of Hygiene, Gyáli ut 2-4, H-1966 Budapest, Hungary. 